\title{
Extracellular RNA: mechanisms of it's transporting into target cells
}

\author{
Kuan-Chen Lu $^{1 \dagger}$, Yujing Zhang ${ }^{1 \dagger}$ and Eli Song ${ }^{2^{*}}$ (D)
}

\begin{abstract}
Extracellular RNA (exRNA) is a type of RNA fragment that presents in extracellular fluids with highly stable features. It is carried by vesicles, such as exosomes, apoptotic bodies and other microvesicles, or associated with protein complexes or high-density lipoprotein (HDL). Literature in the past ten years has reported the species of exRNAs in biofluids and the carriers or mediators in exRNA involved cell-to-cell communication. Recently, studies have identified exRNAs to be biomarkers for cancer and other diseases. In addition, mechanisms of exRNA uptake in recipient cells have been reported, especially exosome-mediated transfer. In this review, we will focus on the relevance between exRNAs and their carriers. Furthermore, we will describe the possible ways target cells uptake these carriers with exRNAs.
\end{abstract}

Keywords: RNA, Extracellular RNA, Extracellular vesicles, HDL, Argonaute2, Intercellular communication

\section{Background}

\section{Extracellular RNA}

Extracellular RNA (exRNA) is a type of RNA species that exists in the extracellular fluid and multiple body fluid [1], including in the bloodstream, serum [2], saliva [3], breast milk [4], urine [5], and other biofluids [6, 7]. Previously, classical thinking considered ribonucleases (RNases) outside of cells perform the activity to degrade RNA molecules, often foreign RNAs such as viral RNA, in the extracellular milieu. However, in 2008, Zhang et al. discovered that serum microRNA can resist the digestion of RNase and that the levels of microRNAs (miRNAs) in serum are stable [2]. Thus far, research has shown that some of the exRNAs might maintain their structural stability in the extracellular environment. Some evidence shows that exRNAs are discovered in enclosed conformations or in the form of ribonucleoprotein complexes to prevent degradation. In this review, we will focus on introducing the functions and applications of exRNAs and the ways exRNAs are taken up by recipient cells.

\footnotetext{
*Correspondence: songali@ibp.ac.cn

${ }^{\dagger}$ Kuan-Chen Lu and Yujing Zhang contributed equally to this work.

${ }^{2}$ National Laboratory of Biomacromolecules, CAS Center for Excellence in Biomacromolecules, Institute of Biophysics, Chinese Academy of Sciences, Beijing 100101, China

Full list of author information is available at the end of the article
}

\section{Existing form of exRNA in the extracellular environment} Until now, studies have suggested that different types of exRNA are either encased within various types of vesicles or are tightly associated with proteins to avoid degradation by RNase:

a. Vesicle-associated form In cell biology, diverse types of extracellular vesicles (EVs) have been recognized, such as apoptotic bodies [8], microvesicles (MVs), membrane particles and exosomes [9-11]. All of these vesicles are enclosed structures formed by lipid bilayers. It has become clear over the past few years that extracellular vesicles can play a role as RNA carriers. Numerous studies have focused on the evidence of exosomes as RNA carriers [12, 13], researched by RNA sequencing and/or microarray of purified exosomes [14] and microRNA (miRNA) effector complex localization in multivesicular bodies (MVBs) $[15,16]$. Moreover, a number of different types of RNA molecules have been discovered in EVs, including messenger RNA (mRNA), long non-coding RNA (lncRNA), small non-coding RNA (sncRNA), ribosomal RNA (rRNA) and miRNA [17-20]. These vehicles with exRNAs, presented in the extracellular milieu, could be used to transport protein and RNA cargos 
between donor and recipient cells and affect the gene expression and relevant phenotype presented by recipient cells [12, 13, 21-24].

b. Non-vesicle-associated form

In addition, evidence has suggested that some carriers independent of vesicles can play a role as RNA molecule carriers: Argonaute2 (Ago2) protein complexes have the capacity to carry circulating microRNAs in human plasma [25] and lipoprotein protein particles, mainly by high-density lipoproteins (HDLs), transporting endogenous miRNAs to recipient cells in extracellular fluid [26].

\section{The role of exRNA as a biomarker}

Contrasted with parental cells, some RNA molecules are enriched in EVs [12, 13, 27]. Recent studies have supported that the application of exRNA in extracellular fluid could be a biomarker recognition in diseases [28], including cancer. For human health, studies reporting exRNA to be biomarkers of cancer can raise the accuracy of clinical diagnosis. In addition, not only can EVs be tumour cell-derived exRNA carriers but can also be found in human biofluids, such as urine [29], serum, plasma [13], cerebrospinal fluid [30], breast milk and saliva [31]. Thus, studies on the relevance between exRNAs and cancer-specific biomarkers have been investigated:

a. Potential biomarker of EV-associated mRNA Several papers indicate that cancer cell-derived EVs contain particular mRNAs in an elevated level [32]: in prostate cancer, exosomes from the urine of showed specific biomarkers of mRNAs and RNA transcripts [33]; in gastric cancer, mRNAs of VEGF, IL-6 and RANTES increased in blood EVs [34]; in colon cancer, LISCH7 mRNA were enriched in plasma EVs [35].

b. Distinctive mRNA transcriptomes Some studies describe characteristic mRNA transcriptomes from patients with cancer have been discovered in saliva, and the transcriptomic signatures can serve as biomarkers in cancer detection, including breast cancer [36], ovarian cancer [37], and pancreatic cancer [38].

c. miRNAs

Current research has focused on whether the biofluid level of miRNAs can be a source of cancer biomarkers. Notably, studies indicate that patients with lung cancer [17], ovarian cancer [19] and oesophageal squamous cell carcinoma [39] have abnormal characteristic profiles of miRNA levels in their serum. In addition, a similar phenomenon was observed in the saliva of patients with oral cancer [40]. Moreover, EVs released from other types of cancer comprise their individual profiles of
miRNAs, such as liver cancer [41], prostate cancer $[33,42]$ and colorectal cancer [43].

d. Other ncRNAs

Some evidence indicates that high levels of noncoding RNAs (ncRNAs), including lncRNA, small interfering RNA (siRNA), piwi-interacting RNA (piRNA), and small nuclear RNA (snRNA), have been discovered in EVs from patients with cancer $[14,44]$, such as glioma and brain tumour microvesicles $[27,45]$.

\section{Mechanisms of transporting exRNA to recipient cells}

It has been proposed that once the exRNAs are transported out of the donor cells, three possibly competent carriers might be a mediator to deliver the RNA cargos to the recipient cells: exosomes (or other vesicles), HDL, or Ago2 protein complexes [46]. These types of cell-to-cell communication are the key aspect in many biological processes as follows:

\section{a. Exosomes}

Exosomes are the smallest vesicle in all of the endosomal-derived vesicles [47],believed to form by invagination into intraluminal vesicles, as a whole termed MVBs. In addition, exosomes in MVBs can not only transport and fuse into lysosomes for degradation but can also release into the extracellular space by fusing with the plasma membrane [48]. To date, the function and role of exosomes as mediators in intercellular communication have been widely investigated [49-51]. In addition, some of the RNA materials comprised in EVs can transport to recipient cells and translate to form protein products, depending on the length, class and characteristic of the RNA molecules [52]. Small RNAs, especially miRNAs, can be transported by EVs effectively and regularly perform their molecular function in recipient cells [53-55].

Three principal mechanisms have been proposed for exRNA delivered from EVs to enter into the recipient cells [56]: (i) exRNAs in exosomes can be transported into target cells through multiple pathways: endocytosis, caveolin-mediated endocytosis, clathrin-mediated endocytosis, lipid raft-mediated endocytosis, macropinocytosis, phagocytosis and/or pinocytosis, etc. [57, 58]; (ii) exRNAs in exosomes can be transported into the target cells by the particular membrane receptors matched up to the exosomal ligands [59-61]; and (iii) exRNA carried by exosomes can release the RNA molecules in vesicles inside the recipient cell cytoplasm by fusing vesicular and cellular membranes together in a non-selective manner. 
The internalizing process of membrane fusion can incorporate new surface membrane receptors (exosome-membrane originated) and separate lipid components to modify the recipient cells. Other molecules from exosomes can trigger signal pathways and metabolic events in the target cells.

b. High-density lipoprotein (HDL) [26]

(a) HDL transfers miRNAs to recipient cells (Kasey C. Vickers, Brain T. Palmisano).

The Vickers group has discovered that ATP-binding cassette transporter A1 (ABCA1) might be involved in the mechanism of miRNA export by HDL. Previously, it was known that during the biogenesis process of HDL, ABCA1 cellular efflux can transform cholesterol and phospholipids into nascent HDL [62]. By inducing the overexpression of ABCA1 in J774 mouse macrophages, they found that the abundance of miR-223 increased. In addition, treating recipient cells (hepatocytes) with the HDL-miR-335 complex (native HDL and exogenous miR-335 incorporated together), they found that the miR-335 level in the intracellular environment increased 11.8 -fold. These results indicate the capacity of HDL to deliver genetic materials.

(b) Intercellular communication by HDL

To confirm whether endogenous levels of miRNAs delivered by HDL are sufficient to affect gene expression in target cells, the Vickers group treated hepatocytes (Huh7) with familial hypercholesterolemia HDL and healthy HDL, respectively. Compared with familial hypercholesterolemia HDL, healthy HDL lacks hsamiR-105, which can be found in hypercholesterolemia HDL only. In addition, Huh7 cells can express hsamiR-105 by itself. Treatment of healthy HDL to Huh7 cannot alter the intracellular level of miR-150. On the other hand, cells treated with familial hypercholesterolemia HDL, containing ample levels of hsa-miR-150, can notably increase intracellular levels of miRNAs and have significant gene expression changes. Last but not least, in other research, it has been discovered that HDL-associated miRNAs can be transported into the cells by the transfer of a specific receptor (scavenger receptor class $B$ type 1 ) on the recipient cell membranes [26].

c. Argonaute2 [25]

Application of Argonaute2 with exRNA carrying capacity.

Although the mechanism by which recipient cells take up the Ago2-miRNA complex is still unknown, the relevance between exRNA and Argonaute2 has been revealed.
According to research by the Jason D. Arroyo group, evidence supports the hypothesis that $90 \%$ of circulating miRNAs are associated with non-membrane enclosed ribonucleoprotein complexes. They also hypothesized that miRNAs associated with vesicles or Ago2 protein complexes originated from different cell types and present distinct mechanisms of miRNA expression or release in particular cells. Other studies support their hypothesis; hepatocyte-specific miRNA miR-122 can only be found and detected in the protein-associated fractions. This result indicates that liver cells may release their unique miRNA through a protein complex [63]. In contrast, the other miRNAs belonging to the vesicle-associated RNAs might derive from cells that have the capacity to generate vesicles, such as reticulocytes that release exosomes containing miR-let-7a [64] during cell maturation and platelets that release microvesicles and exosomes during the activation stage $[65,66]$.

\section{Conclusion}

Currently, extracellular RNA discovery is ground-breaking in molecular biology. The evidence of detecting exRNAs in biofluids and carriers, including EVs, HDL and Ago2, sheds new light on the field of establishing disease biomarkers; examples of this include high levels of specific mRNA in exosomes, distinctive mRNA transcriptomes in saliva and circulating miRNA as potential biomarkers. In addition, studies investigating exRNAs in the role of cell-to-cell communication determined the relevant mechanisms and interactions between recipient cells and exRNA carriers. Studies have shown that the multiple ways for exosomes to enter target cells and HDLs are mediators involved in the uptake of miRNAs in hepatocytes. Nonetheless, although the capacity of Ago2 to be a carrier of circulating miRNA in human serum has been reported, it is still unknown whether Ago2 can mediate exRNA taken up by target cells. Finally, at an objective angle, the mechanism of intercellular communication in exRNAs and their carriers could be the focus of future research. In addition, other undiscovered vehicles for carrying exRNA and the relevance of molecular function in cell biology can be explored in the future.

\footnotetext{
Abbreviations

ABCA1: ATP-binding cassette transporter A1; Ago2: Argonaute2; EV: extracellular vesicle; exRNA: extracellular RNA; HDL: high-density lipoprotein; IncRNA: long non-coding RNA; miRNA: microRNA; mRNA: messenger RNA; MVs: microvesicles; ncRNA: non-coding RNA; piRNA: piwi-interacting RNA; RNase: ribonuclease; rRNA: ribosomal RNA; siRNA: small interfering RNA; sncRNA: small non-coding RNA; snRNA: small nuclear RNA
}

Acknowledgements Not applicable. 


\section{Funding}

This work was financially supported by grants from Ministry of Science and Technology of the People's Republic of China (2018YFA0507100), the National Natural Science Foundation of China (31770900), National Key Research and Development Program (2018YFA0507101).

\section{Availability of data and materials}

Not applicable.

\section{Authors' contributions}

$\mathrm{KCL}$ wrote the article. $\mathrm{YZ}$ and $\mathrm{ES}$ directed the project. All authors read and approved the final manuscript.

\section{Ethics approval and consent to participate}

Not applicable.

\section{Consent for publication}

Not applicable.

\section{Competing interests}

The authors declare that they have no competing interests.

\section{Publisher's Note}

Springer Nature remains neutral with regard to jurisdictional claims in published maps and institutional affiliations.

\section{Author details}

${ }^{1}$ State Key Laboratory of Pharmaceutical Biotechnology, Collaborative Innovation Centre of Chemistry for Life Sciences, Jiangsu Engineering Research Centre for MicroRNA Biology and Biotechnology, NJU Advanced Institute for Life Sciences (NAILS), School of life sciences, Nanjing University, 163 Xianlin Road, Nanjing 210023, Jiangsu, China. ${ }^{2}$ National Laboratory of Biomacromolecules, CAS Center for Excellence in Biomacromolecules, Institute of Biophysics, Chinese Academy of Sciences, Beijing 100101, China.

\section{Received: 19 July 2018 Accepted: 14 March 2019}

\section{Published online: 02 July 2019}

\section{References}

1. Dinger ME, Mercer TR, Mattick JS. RNAs as extracellular signaling molecules. J Mol Endocrinol. 2008:40(4):151-9

2. Chen $X$, Ba Y, Ma L, Cai X, Yin Y, Wang K, et al. Characterization of microRNAs in serum: a novel class of biomarkers for diagnosis of cancer and other diseases. Cell Res. 2008;18(10):997.

3. Michael A, Bajracharya SD, Yuen PS, Zhou H, Star RA, Illei GG, et al. Exosomes from human saliva as a source of microRNA biomarkers. Oral Dis. 2010;16(1):34-8.

4. Kosaka N, Izumi H, Sekine K, Ochiya T. microRNA as a new immuneregulatory agent in breast milk. Silence. 2010;1(1):7.

5. Menke TB, Warnecke JM. Improved conditions for isolation and quantification of RNA in urine specimens. Ann N Y Acad Sci. 2004;1022(1): 185-9.

6. Zubakov D, Boersma AW, Choi Y, van Kuijk PF, Wiemer EA, Kayser M. MicroRNA markers for forensic body fluid identification obtained from microarray screening and quantitative RT-PCR confirmation. Int J Legal Med. 2010;124(3):217-26.

7. Hanson EK, Lubenow H, Ballantyne J. Identification of forensically relevant body fluids using a panel of differentially expressed microRNAs. Anal Biochem. 2009;387(2):303-14.

8. Van der Pol E, Böing A, Gool E, Nieuwland R. Recent developments in the nomenclature, presence, isolation, detection and clinical impact of extracellular vesicles. J Thromb Haemost. 2016;14(1):48-56.

9. van der Pol E, Böing AN, Harrison P, Sturk A, Nieuwland R. Classification, functions, and clinical relevance of extracellular vesicles. Pharmacological reviews. 2012:pr. 112.005983.

10. Rak J, editor Microparticles in cancer. Seminars in thrombosis and hemostasis; 2010: (c) Thieme Medical Publishers.

11. Al-Nedawi K, Meehan B, Micallef J, Lhotak V, May L, Guha A, et al. Intercellular transfer of the oncogenic receptor EGFRvIII by microvesicles derived from tumour cells. Nat Cell Biol. 2008;10(5):619.
12. Valadi H, Ekström K, Bossios A, Sjöstrand M, Lee JJ, Lötvall JO. Exosomemediated transfer of mRNAs and microRNAs is a novel mechanism of genetic exchange between cells. Nat Cell Biol. 2007;9(6):654.

13. Skog J, Würdinger T, Van Rijn S, Meijer DH, Gainche L, Curry WT Jr, et al. Glioblastoma microvesicles transport RNA and proteins that promote tumour growth and provide diagnostic biomarkers. Nat Cell Biol. 2008; 10(12):1470.

14. Nolte-'t Hoen EN, Buermans HP, Waasdorp M, Stoorvogel W, Wauben MH, 't Hoen PA. Deep sequencing of RNA from immune cell-derived vesicles uncovers the selective incorporation of small non-coding RNA biotypes with potential regulatory functions. Nucleic Acids Res 2012;40(18):92729285.

15. Gibbings DJ, Ciaudo C, Erhardt M, Voinnet O. Multivesicular bodies associate with components of miRNA effector complexes and modulate miRNA activity. Nat Cell Biol. 2009:11(9):1143.

16. Lee YS, Pressman S, Andress AP, Kim K, White JL, Cassidy JJ, et al. Silencing by small RNAs is linked to endosomal trafficking. Nat Cell Biol. 2009;11(9): 1150

17. Rabinowits G, Gerçel-Taylor C, Day JM, Taylor DD, Kloecker GH. Exosomal microRNA: a diagnostic marker for lung cancer. Clinical lung cancer. 2009; 10(1):42-6.

18. Bellingham SA, Coleman BM, Hill AF. Small RNA deep sequencing reveals a distinct miRNA signature released in exosomes from prion-infected neuronal cells. Nucleic Acids Res. 2012;40(21):10937-49.

19. Taylor DD, Gercel-Taylor C. MicroRNA signatures of tumor-derived exosomes as diagnostic biomarkers of ovarian cancer. Gynecol Oncol. 2008;110(1):1321.

20. Huang $X$, Yuan $T$, Tschannen $M$, Sun $Z$, Jacob H, Du M, et al. Characterization of human plasma-derived exosomal RNAs by deep sequencing. BMC Genomics. 2013;14(1):319.

21. Baj-Krzyworzeka M, Szatanek R, Węglarczyk K, Baran J, Urbanowicz B, Brański $P$, et al. Tumour-derived microvesicles carry several surface determinants and mRNA of tumour cells and transfer some of these determinants to monocytes. Cancer Immunol Immunother. 2006:55(7):808-18.

22. Renzulli JF II, Del Tatto M, Dooner G, Aliotta J, Goldstein L, Dooner M, et al. Microvesicle induction of prostate specific gene expression in normal human bone marrow cells. J Urol. 2010;184(5):2165-71.

23. Crescitelli R, Lässer C, Szabo TG, Kittel A, Eldh M, Dianzani I, et al. Distinct RNA profiles in subpopulations of extracellular vesicles: apoptotic bodies, microvesicles and exosomes. Journal of extracellular vesicles. 2013;2(1): 20677.

24. Panagopoulos K, Cross-Knorr S, Dillard C, Pantazatos D, Del Tatto M, Mills D, et al. Reversal of chemosensitivity and induction of cell malignancy of a non-malignant prostate cancer cell line upon extracellular vesicle exposure. Mol Cancer. 2013;12(1):118.

25. Arroyo JD, Chevillet JR, Kroh EM, Ruf IK, Pritchard CC, Gibson DF, et al. Argonaute2 complexes carry a population of circulating microRNAs independent of vesicles in human plasma. Proc Natl Acad Sci. 2011;108(12): $5003-8$

26. Vickers KC, Palmisano BT, Shoucri BM, Shamburek RD, Remaley AT. MicroRNAs are transported in plasma and delivered to recipient cells by high-density lipoproteins. Nat Cell Biol. 2011;13(4):423.

27. Li CC, Eaton SA, Young PE, Lee M, Shuttleworth R, Humphreys DT, et al. Glioma microvesicles carry selectively packaged coding and non-coding RNAs which alter gene expression in recipient cells. RNA Biol. 2013;10(8): 1333-44.

28. Williams Z, Ben-Dov IZ, Elias R, Mihailovic A, Brown M, Rosenwaks Z, et al. Comprehensive profiling of circulating microRNA via small RNA sequencing of cDNA libraries reveals biomarker potential and limitations. Proc Natl Acad Sci. 2013:201214046.

29. Miranda KC, Bond DT, McKee M, Skog J, Păunescu TG, Da Silva N, et al. Nucleic acids within urinary exosomes/microvesicles are potential biomarkers for renal disease. Kidney Int. 2010;78(2):191-9.

30. Street JM, Barran PE, Mackay CL, Weidt S, Balmforth C, Walsh TS, et al. Identification and proteomic profiling of exosomes in human cerebrospinal fluid. J Transl Med. 2012;10(1):5.

31. Lässer C, Alikhani VS, Ekström K, Eldh M, Paredes PT, Bossios A, et al. Human saliva, plasma and breast milk exosomes contain RNA: uptake by macrophages. J Transl Med. 2011;9(1):9.

32. Redzic JS, Balaj L, van der Vos KE, Breakefield XO. Extracellular RNA mediates and marks cancer progression. Semin Cancer Biol. 2014;28:14-23. 
33. Nilsson J, Skog J, Nordstrand A, Baranov V, Mincheva-Nilsson L, Breakefield $X$, et al. Prostate cancer-derived urine exosomes: a novel approach to biomarkers for prostate cancer. Br J Cancer. 2009;100(10):1603.

34. Kim H, Song K, Park Y, Kang Y, Lee $Y$, Lee $K$, et al. Elevated levels of circulating platelet microparticles, VEGF, IL-6 and RANTES in patients with gastric cancer: possible role of a metastasis predictor. Eur J Cancer. 2003; 39(2):184-91.

35. García JM, García V, Peña C, Domínguez G, Silva J, Diaz R, et al. Extracellular plasma RNA from colon cancer patients is confined in a vesicle-like structure and is mRNA-enriched. Rna. 2008;14(7):1424-32.

36. Zhang L, Xiao H, Karlan S, Zhou H, Gross J, Elashoff D, et al. Discovery and preclinical validation of salivary transcriptomic and proteomic biomarkers for the non-invasive detection of breast cancer. PLoS One. 2010;5(12): e15573

37. Lee Y-H, Kim JH, Zhou H, Kim BW, Wong DT. Salivary transcriptomic biomarkers for detection of ovarian cancer: for serous papillary adenocarcinoma. J Mol Med. 2012;90(4):427-34.

38. Zhang L, Farrell JJ, Zhou H, Elashoff D, Akin D, Park NH, et al. Salivary transcriptomic biomarkers for detection of resectable pancreatic cancer. Gastroenterology. 2010;138(3):949-957. e7.

39. Takeshita N, Hoshino I, Mori M, Akutsu Y, Hanari N, Yoneyama Y, et al. Serum microRNA expression profile: miR-1246 as a novel diagnostic and prognostic biomarker for oesophageal squamous cell carcinoma. $\mathrm{Br} \mathrm{J}$ Cancer. 2013;108(3):644.

40. Yoshizawa JM, Wong DT. Salivary microRNAs and oral cancer detection. MicroRNA Protocols: Springer; 2013. p. 313-24.

41. Gailhouste L, Gomez-Santos L, Ochiya T. Potential applications of miRNAs as diagnostic and prognostic markers in liver cancer. Front Biosci (Landmark Ed). 2013:18:199-223.

42. Bryant R, Pawlowski T, Catto J, Marsden G, Vessella R, Rhees B, et al. Changes in circulating microRNA levels associated with prostate cancer. $\mathrm{Br} J$ Cancer. 2012;106(4):768.

43. Chiba M, Kimura M, Asari S. Exosomes secreted from human colorectal cancer cell lines contain mRNAs, microRNAs and natural antisense RNAs, that can transfer into the human hepatoma HepG2 and lung cancer A549 cell lines. Oncol Rep. 2012;28(5):1551-8.

44. Balaj L, Lessard R, Dai L, Cho Y-J, Pomeroy SL, Breakefield XO, et al. Tumour microvesicles contain retrotransposon elements and amplified oncogene sequences. Nat Commun. 2011;2:180.

45. van der Vos KE, Balaj L, Skog J, Breakefield XO. Brain tumor microvesicles: insights into intercellular communication in the nervous system. Cell Mol Neurobiol. 2011;31(6):949-59.

46. Patton JG, Franklin JL, Weaver AM, Vickers K, Zhang B, Coffey RJ, et al. Biogenesis, delivery, and function of extracellular RNA. Journal of extracellular vesicles. 2015;4(1):27494.

47. Théry C, Zitvogel L, Amigorena S. Exosomes: composition, biogenesis and function. Nat Rev Immunol. 2002;2(8):569.

48. Keller S, Sanderson MP, Stoeck A, Altevogt P. Exosomes: from biogenesis and secretion to biological function. Immunol Lett. 2006;107(2):102-8.

49. Simons M, Raposo G. Exosomes-vesicular carriers for intercellular communication. Curr Opin Cell Biol. 2009;21(4):575-81.

50. Lopez-Verrilli MA. Exosomes: mediators of communication in eukaryotes. Biol Res. 2013;46(1):5-11.

51. Muralidharan-Chari V, Clancy JW, Sedgwick A, D'Souza-Schorey C. Microvesicles: mediators of extracellular communication during cancer progression. J Cell Sci. 2010;123(10):1603-11.

52. Ratajczak J, Miekus K, Kucia M, Zhang J, Reca R, Dvorak P, et al. Embryonic stem cell-derived microvesicles reprogram hematopoietic progenitors: evidence for horizontal transfer of mRNA and protein delivery. Leukemia. 2006;20(5):847.

53. Zhang Y, Liu D, Chen X, Li J, Li L, Bian Z, et al. Secreted monocytic miR-150 enhances targeted endothelial cell migration. Mol Cell. 2010;39(1):133-44.

54. Yang M, Chen J, Su F, Yu B, Su F, Lin L, et al. Microvesicles secreted by macrophages shuttle invasion-potentiating microRNAs into breast cancer cells. Mol Cancer. 2011:10(1):117.

55. Villarroya-Beltri C, Gutiérrez-Vázquez C, Sánchez-Madrid F, Mittelbrunn M. Analysis of microRNA and protein transfer by exosomes during an immune synapse. Circulating MicroRNAs: Springer; 2013. p. 41-51.

56. Mathivanan S, Ji H, Simpson RJ. Exosomes: extracellular organelles important in intercellular communication. J Proteome. 2010:73(10):1907-20.
57. Svensson KJ, Christianson HC, Wittrup A, Bourseau-Guilmain E, Lindqvist E, Svensson LM, et al. Exosome uptake depends on ERK1/2-heat shock protein 27 signalling and lipid raft-mediated endocytosis negatively regulated by caveolin-1. Journal of Biological Chemistry. 2013; jbc. M112. 445403.

58. Zhou Y, Zhou G, Tian C, Jiang W, Jin L, Zhang C, et al. Exosome-mediated small RNA delivery for gene therapy. Wiley Interdisciplinary Reviews: RNA. 2016;7(6):758-71.

59. Ekström K, Valadi H, Sjöstrand M, Malmhäll C, Bossios A, Eldh M, et al. Characterization of mRNA and microRNA in human mast cell-derived exosomes and their transfer to other mast cells and blood CD34 progenitor cells. Journal of extracellular vesicles. 2012;1(1):18389.

60. Montecalvo A, Larregina AT, Shufesky WJ, Stolz DB, Sullivan ML, Karlsson JM, et al. Mechanism of transfer of functional microRNAs between mouse dendritic cells via exosomes. Blood. 2011; blood-2011-02-338004.

61. Mittelbrunn M, Gutiérrez-Vázquez C, Villarroya-Beltri C, González S, SánchezCabo F, González MÁ, et al. Unidirectional transfer of microRNA-loaded exosomes from T cells to antigen-presenting cells. Nat Commun. 2011;2:282.

62. Lund-Katz S, Phillips MC. High density lipoprotein structure-function and role in reverse cholesterol transport. Cholesterol Binding and Cholesterol Transport Proteins: Springer; 2010. p. 183-227.

63. Chang J, Nicolas E, Marks D, Sander C, Lerro A, Buendia MA, et al. miR-122, a mammalian liver-specific microRNA, is processed from hcr mRNA and maydownregulate the high affinity cationic amino acid transporter CAT-1. RNA Biol. 2004;1(2):106-13.

64. Blanc L, Vidal M. Reticulocyte membrane remodeling: contribution of the exosome pathway. Curr Opin Hematol. 2010:17(3):177-83.

65. Heijnen HF, Schiel AE, Fijnheer R, Geuze HJ, Sixma JJ. Activated platelets release two types of membrane vesicles: microvesicles by surface shedding and exosomes derived from exocytosis of multivesicular bodies and --granules. Blood. 1999;94(11):3791-9.

66. Hunter MP, Ismail N, Zhang X, Aguda BD, Lee EJ, Yu L, et al. Detection of microRNA expression in human peripheral blood microvesicles. PLoS One. 2008:3(11):e3694.

\section{Ready to submit your research? Choose BMC and benefit from:}

- fast, convenient online submission

- thorough peer review by experienced researchers in your field

- rapid publication on acceptance

- support for research data, including large and complex data types

- gold Open Access which fosters wider collaboration and increased citations

- maximum visibility for your research: over $100 \mathrm{M}$ website views per year

At $\mathrm{BMC}$, research is always in progress.

Learn more biomedcentral.com/submissions 